\title{
$\mathrm{DSP}$ 보드를 이용한 가상의 리더와 태그 에뮬레이터 시스템 구현
}

\author{
김영춘 ${ }^{1}$, 주해종 $^{2}$, 최혜길 ${ }^{*}$, 조문택 ${ }^{4}$ \\ ${ }^{1}$ 공주대학교 기계자동차공학부, ${ }^{2}$ 동국대학교 산학협력중심대학 \\ ${ }^{3}$ 경희사이버대학교 정보통신학과, ${ }^{4}$ 대원대학 전기전자계열
}

\section{Implementation of Virtual Reader and Tag Emulator System Using DSP Board}

\author{
Young-Choon Kim ${ }^{1}$, Hae-Jong Joo $^{2}$, Hae-Gill Choi ${ }^{3^{*}}$ and Moon-Taek Cho ${ }^{4}$ \\ ${ }^{1}$ Division of Mechanical Automotive Engineering, Kongju National University \\ ${ }^{2}$ HUNIC, DongKuk University \\ ${ }^{3}$ Department of Information \& Telecommunication, Kyung Hee Cyber University \\ ${ }^{4}$ Division of Electrical \& Electronic Engineering, Daewon University College
}

\begin{abstract}
요 약 신호를 생성할 수 있는 상용 신호 생성 장치 그리고 데이터 수집 장비와 DSP 보드를 이용하여 가상의 리더 와 태그를 모델링 한 에뮬레이터 시스템을 구현했다.

개발한 가상의 UHF RFID $\left(860^{\sim} 960[\mathrm{MHz}]\right)$ 리더/태그 모듈을 이용하여 개발한 RFID 리더와 태그의 프로토콜 및 RF 특성 등이 국제 표준 규격(ISO 18000-6 Type C, EPCglobal C1G2)에 적합 여부를 검증할 수 있는 방법을 제공해 줄 수 있게 하였다.

본 논문에서 제안한 가상의 리더 모델과 태그 모델을 구현하기 위해 DSP 보드를 이용하여 Visual DSP로 구현하였으 며, 시스템의 신호발생기, 신호 분석기, 성능 검증 대상 리더 또는 태그, RFID 에뮬레이터 제어 컴퓨터 및 제어 프로 그램으로 구성하였다.
\end{abstract}

\begin{abstract}
Modeling a virtual reader and tags, the emulator system is realized by using a commercial signal generation device to make signal, a data collection equipment, and DSP board. By using a Virtual UHF RFID $(860 \sim 960[\mathrm{MHz}])$ reader/tags module, a developed RFID reader, protocol of tag, and properties of RF support to provide the way how to verify the suitability to international standards (ISO 18000-6 Type C, EPCglobal C1G2).

In this paper, to implement a proposed model reader and tag model, Visual DSP is applied by using DSP board, composing the system's signal generators, signal analyzers and performance verification, the target readers or tags, RFID emulator control computesr and control programs
\end{abstract}

Key Words : RFID DSP Emulator

1. 서론

RFID(Radio Frequency IDentification)는 무선 신호를 통해 비접촉식으로 사물에 부착된 얇은 평면 형태의 태 그를 식별 하여 정보를 처리하는 시스템이다. RFID 원천 기술의 확보 및 국제적인 표준화 선도를 통한 국가 경쟁
력의 향상, 세계적인 RFID 클러스터 조성을 통한 산업발 전에의 기여를 하기 위해 현재 국내외 학계와 산업계에 서 수많은 RFID 관련 논문과 기술이 연구 되고 있다.

특히 지식경제부 기술표준원은 RFID/USN의 표준화 협력체계를 강화하기 위해 "RFID/USN표준화 통합협의 회”의 공식 출범회의를 갖고 본격적인 활동을 시작하여

*교신저자 : 최혜길(hgchoi@khcu.ac.kr)

접수일 10년 06월 21일 수정일 (1차 10년 10월 01일, 2차 10년 10월 14일)

게재확정일 10 년 10 월 15 일 
국내 RFID/USN기술 개발과 확산사업 및 인프라구축 등 관련 산업 정책과 표준화 연계를 강화하여 우리나리 원 천 기술의 국제 표준 반영에 주력 하고 응용산업 활성화 를 위한 시장 표준화를 추진하고 있다.

따라서 수많은 RFID 관련 업체와 연구 기간에서 개발 된 리더와 태그가 국제 표준 규격과 각국의 RF 규격에 부합되는 적합한 시스템인지를 판단하는 것이 중요한 요 소로 부각되고 있으며, 개발한 리더 및 태그의 성능 평가 도 중요한 사항이다.

본 논문에서는 DSP 보드를 이용하여 RFID 리더/태그 에뮬레이터를 구현하고 신호 생성 기, 신호 분석기를 이 용하여 대상 RFID 리더 또는 태그의 성능 검증 및 성능 모의실험을 할 수 있는 환경을 개발하였다.

RFID기술 개요와 ISO 18000-6 등의 규격은 각각 참고 문헌 $[1,2]$ 에 상세히 정리 되어 있다.

\section{2. 에뮬레이터 시스템}

개발된 에뮬레이터는 가상의 리더와 태그의 기능이 모 두 가능하며, 태그의 적합성을 테스트하거나 개발 중인 리더의 성능을 시뮬레이션 하려면 가상의 태그 기능을 적용하여 측정하고, 태그의 성능을 시뮬레이션 하려면 가 상의 리더 기능을 적용하여 측정할 수 있다. 에뮬레이션 하기 위한 전체적인 구성은 신호 발생기, 신호 분석기, RFID 리더/태그 에뮬레이터, 제어컴퓨터, 제어 프로그램 으로 이루어진다.

가상의 RFID 리더 모듈로 동작하기 위해서 Visual DSP 프로그램을 이용하여 ISO 18000-6 Type C 리더 모 델에 해당하는 프로토콜을 구현하고 구현된 데이터를 Baseband로 변환하여 변환된 $\mathrm{I} / \mathrm{Q}$ 데이터를 상용 신호발 생기의 Video Out 단자로 보내 신호발생기에 연결된 안 테나를 통하여 대상 태그로 실제 무선 신호를 방사한다. 태그로부터 방사된 신호를 신호분석기에서 입력받아 에 뮬레이터에서 데이터를 분석하고 적합성을 판단한다.

가상의 RFID 태그 모듈로 동작하기 위해서 Visual DSP 프로그램을 이용하여 ISO 18000-6 type C 태그 모 델에 해당하는 프로토콜을 구현 하고 대상 리더로부터 송출된 신호를 신호 분석기로 입력 받아 수신된 $\mathrm{I} / \mathrm{Q}$ 데이 터를 Video Out 단자를 통해 에뮬레이터에서 입력 받아 신호를 분석하고 적합성을 판단하고 수신된 리더 명령어 에 따라 가상의 태그는 모듈에서 규격에 적합한 신호를 생성하여 신호 발생기로 송출 한다. 이와 같은 방법으로 실제 리더 및 태그 설계에 대한 테스트를 할 수 있다.

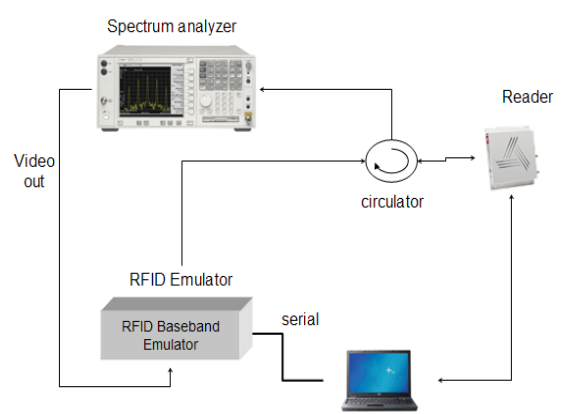

[그림 1] 상용 장비를 이용한 RFID 태그 에뮬레이터 구성도

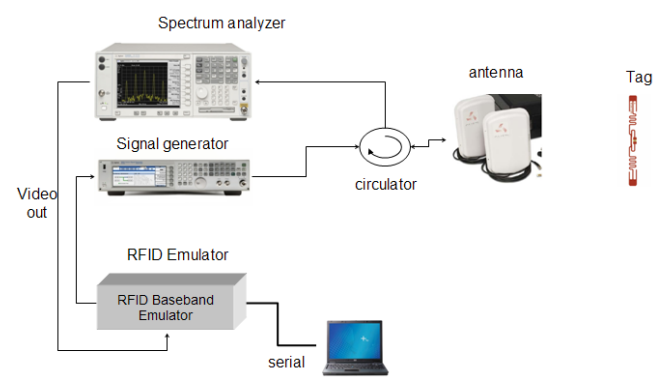

[그림 2] 상용 장비를 이용한 RFID 리더 에뮬레이터 구성도

\section{3. 구현}

\section{1 시스템 구성}

본 논문에서는 RFID baseband 에뮬레이터는 DSP 보 드(Blackfin)와 Switching Box로 구성 되어있으며, ISO 18000-6 Type C 규격에 적합한지를 측정하기 위해 신호 발생기, 신호 분석기, 실험대상 RFID 리더 또는 태그 등 으로 구성된다.

에뮬레이터가 가상의 리더 또는 태그로 동작 하기 위 해서는 DSP 보드에 Visual DSP 프로그램을 이용하여 리 더/태그 명령어, 데이터 encoding/decoding, modulation/ Demodulation 기능을 구현한다.

대상 태그를 검증하기 위해서는 에뮬레이터가 가상의 리더 모듈로 동작 하여 신호를 생성하여 태그로부터 방 사된 신호를 분석 하여 규격에 적합한지를 판단한다.

대상 리더를 검증하기 위해서는 에뮬레이터가 가상의 태그 모듈로 동작 하여 대상 리더로 부터 송출된 신호를 신호 분석기로 수신 하여 에뮬레이터에서 신호 분식 및 규격에 적합한지를 판단하고 리더 명령에 상응하는 데이 터를 대상 리더로 송출한다.

전체 시스템 구성도는 그림 3 과 같다. 


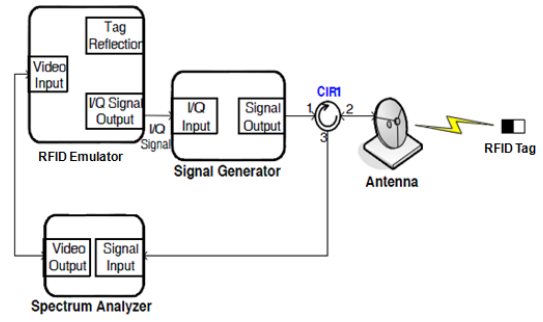

[그림 3] 전체 시스템 구성도

RFID Emulator는 본 논문에서 구현을 하는 매우 중요 한 요소이며, RFID Reader 및 Tag의 신호를 생성 및 측 정을 하는 매우 중요한 요소이다. Signal Generator는 RFID Emulator에서 생성된 IQ신호를 RF로 송출하는데 사용 되며, Signal Analyzer는 RFID Tag 또는 Reader에서 송출 되는 신호를 수신하여 신호가 정확하게 수신되었는 지 판단하는데 사용 된다.

\section{2 에뮬레이터 구현}

\subsubsection{RFID 태그/리더 에뮬레이터 디자인}

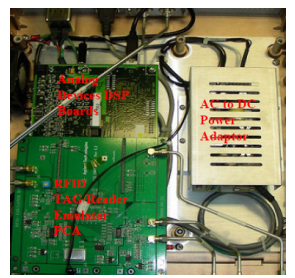

[그림 4] 에뮬레이터 하드웨어 구성

RFID 에뮬레이터는 2개의 주요 보드로 구성 되어있 다. 하나는 Analog Device의 DSP 프로세서 보드이고 다 른 하나는 RFID 태그/리더 에뮬레이터 보드이다.

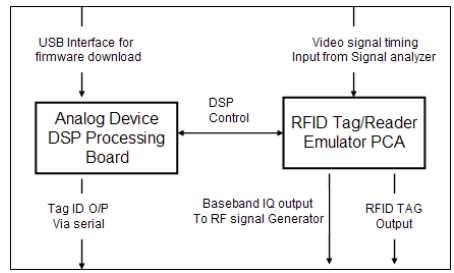

[그림 5] 하드웨어 함수 블럭

DSP 프로세서 보드는 RFID 리더/태그 프로토콜의 Handshaking을 수행하기 위해 신호 분석기로부터 Reference Time을 입력받고, RFID Baseband I/Q decoding 그리고 encoding 기능을 수행한다.

RFID 태그/리더 에뮬레이터 보드는 DSP보드의
Digital I/O 포트를 제어하여 연속적인 Analog IQ 신호를 Digital I/Q 신호로 변환하는 기능을 수행한다.

\subsection{RFID 태그/리더 에뮬레이터 모델}

RFID 에뮬레이터에 모델을 실제 리더의 명령어를 전 송하고 Tag로부터 응답신호를 받아 분석하여 그에 상응 하는 신호를 송출 하는 RFID 리더 모델 과 가상의 Tag로 동작하여 리더로부터 수신된 신호를 분석하여 그에 상응 하는 응답을 보내는 RFID 태그 모델로 구성되어 있다.

$\mathrm{RFID}$ 리더 $\mathrm{Tx}$ 모델은 실제 리더가 동작되는 것과 같 이 리더 Command를 베이스 밴드 신호로 변환 하고 변환 된 신호를 $\mathrm{I} / \mathrm{Q}$ 데이터로 변환하여 신호 발생기를 이용하 여 송출 한다. 신호 생성 과정은 그림 5 와 같다.

리더 Command는 ISO 18000-6 Type C에 해당하는 명 령어를 구현하고, Data encoding는 ISO 18000-6 Type C 에 정의되어 있는 PIE, Miller, FM0 구현한다. 또한 Modulation는 ISO 18000-6 Type C에 정의 되어 있는 ASK, PSK Modulation을 구현한다.

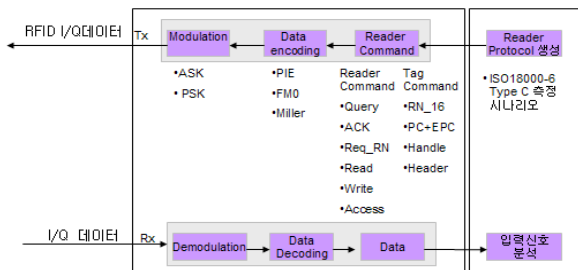

[그림 6] RFID 리더/태그 $\mathrm{Tx}, \mathrm{Rx}$ 신호 생성 및 분석 과정

RFID 리더 Rx 모델은 태그로부터 응답 신호를 신호 분석기로 수신하여 수신된 데이터를 에뮬레이터로 입력 하여 신호를 분석, 태그 UID를 추출하고 다음 명령어를 선택 하여 리더 $\mathrm{Tx}$ 모델로 송출한다.

$\mathrm{RFID}$ 태그 $\mathrm{Tx} / \mathrm{Rx}$ 모델을 리더로부터 수신된 신호를 분석하여 실제 태그가 동작하는 것과 같이 리더의 명령 에 따라 태그 데이터를 그림 5 와 같은 과정을 통해 송출 한다.

\section{4. 실험 및 응용}

RFID 에뮬레이터와 신호 생성 장치, 신호 분석기를 접 목하여 개발한 태그가 국제 표준 규격 (ISO/IEC 18000-6 Type C)에 적합한지를 테스트 해볼 수 있다. 또한 개발한 리더가 국제 표준규격에 적합한지를 테스트 해 볼 수 있 다. 한 예로 RFID 에뮬레이터를 가상의 리더로 동작하게 
하고 생성된 신호를 신호발생기로 송출하면 그 태그에서 방사된 신호를 신호분석기에서 수신하여 RFID 에뮬레이 터에 보내어 분석할 수 있다. 수신된 신호가 국제 표준규 격에 명시되어 있는 요구 사항에 적합 한지 $\mathrm{ASK}$ modulation depth, SAK RF Envelop, Timing 등을 측정할 수 있다.

\subsection{RFID 리더 RF 특성 테스트 및 태그 인식 성능 실험}

본 논문에서는 RFID 에뮬레이터와 신호 발생기, 신호 분석기, 오실로스코프를 이용하여 실제 리더의 $\mathrm{RF}$ 특성 테스트 및 태그의 인식 성능을 실험 하였다.

실험 구성은 그림 1 과 같이 제작한 RFID 에뮬레이터, 신호 분석기, 오실로스코우프, RFID 패치 안테나 그리고 실험 대상 리더로 이루어져 있다. 또한 신호 분석을 위해 VSA(Vector Signal Analysis) Software를 이용하였다.

표준 적합성 표준 규격[3]에서는 전자파차폐실 등과 같은 RFID전파의 간섭이 발생하지 않는 장소에서 실시 하는 것을 권고 하고 있으나 환경 구성 여건상 최대한 전 파간섭이 발생하지 않는 실험실에서 측정한다.

\subsubsection{RFID 리더 RF 특성 테스트}

리더는 국제표준 별로 아래 그림과 같이 데이터 전송 조건을 설정하여 시험한다.

[표 1] 리더 테스트 설정 조건

\begin{tabular}{|c|c|c|c|}
\hline \multicolumn{2}{|c|}{ 국제표준 } & 전송속도 & 명령Preamble 조건 \\
\hline \multirow{2}{*}{$\begin{array}{c}\text { ISO } \\
18000-6 \mathrm{C}\end{array}$} & DSB-ASK 변조 & Tari $=25$ us 권고 & \multirow{2}{*}{$\begin{array}{c}\text { FM0 또는 Miller subcarrier 신 } \\
\text { 호가 } \mathrm{fc} \pm 100 \mathrm{kHz} \text { 이내에 } \\
\text { backscattering 되게 리더명령 } \\
\text { 생성 }\end{array}$} \\
\hline & $\begin{array}{l}\text { PR-ASK 또는 } \\
\text { SSB-ASK 변조 }\end{array}$ & $\begin{array}{c}\text { Tari }=12.5 \sim 25 \text { us 범위 중 } \\
\text { 선택 }\end{array}$ & \\
\hline
\end{tabular}

또한 리더시험 항목 중 $\mathrm{ASK}$ 변조 지수, $\mathrm{ASK} \mathrm{RF}$ Envelop, 스팩트럼 마스크, 리더 명령 Preamble, 리더명령 $\mathrm{T} 2$ 송신 타이밍, 리더 명령 T3 \& T4 송신 타이밍만을 측 정 하였다.

-ASK 변조지수

표준 명령 (ISO 18000-6 Type C: Select : Query)에 대 한 ASK 변조 신호를 최대 파워로 송출한다. Data-0 및 data-1의 ASK 변조도를 오실로스코프에서 측정 하고 ISO 18000-6 Type C에서 권고[1]에 적합한지 판정한다.

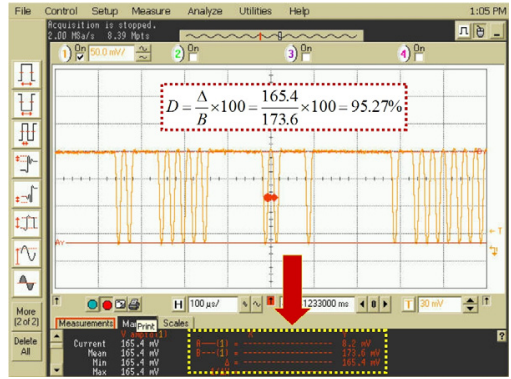

[그림 7] ASK 변조 지수 측정 결과

ASK 변지지수 도출 공식 $\mathrm{D}=(\Delta / \mathrm{B}) \times 100$ 에 따라 $\mathrm{D}=(165.4 / 173.6) \times 100=95.27 \%$ 가 나오는 것을 확인 할 수 있다.

- ASK RF Envelop

리더에서 송신 하는 ASK 변조신호의 포락선 (Envelop)이 표준에서 정한 파형으로 동작하는가를 측정 한다. 측정 결과는 아래 그림과 같다

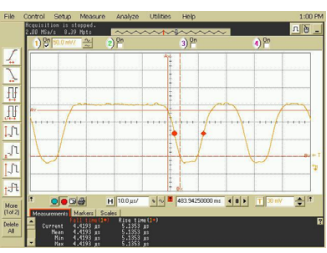

Falling Time

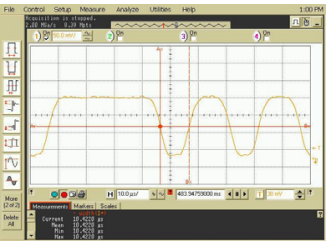

Pulse width

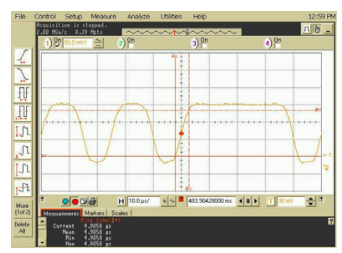

Rising Time

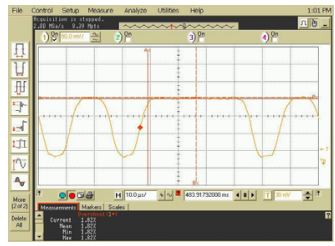

Ripple
[그림 8] ASK RF Envelop 측정 결과

ASK RF Envelop 표준 요구 규격 사양과 비교하면 아 래 표와 같다.

[표 2] ASK RF Envelop 측정 결과

\begin{tabular}{|l|l|c|}
\hline \multicolumn{1}{|c|}{ 항목 } & \multicolumn{1}{|c|}{ 규격 요구 사양 } & 측정 결과 \\
\hline \hline RF Pulsewidth & $\begin{array}{l}\text { Min: Max(0.265 Tari, } \\
\text { 2us) Max:0.525Tari }\end{array}$ & $10.422 \mathrm{us}$ \\
\hline Rise time & Max 500us & $4.9058 \mathrm{us}$ \\
\hline Fall time & Max 500us & 5.1353us \\
\hline
\end{tabular}


-스팩트럼 마스크

리더에서 통신채널로 변조신호를 송출하는 동안, 통신 채널과 인접 채널에 걸친 스팩트럼 마스트가 표준 규격 기준을 만족하는가를 측정한다.

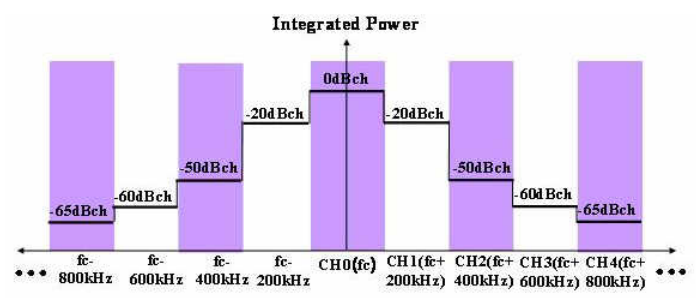

[그림 9] Spectrum Mask 규격 사양

측정 결과는 아래와 같다. (신호 분석을 위해 VSA를 이용)

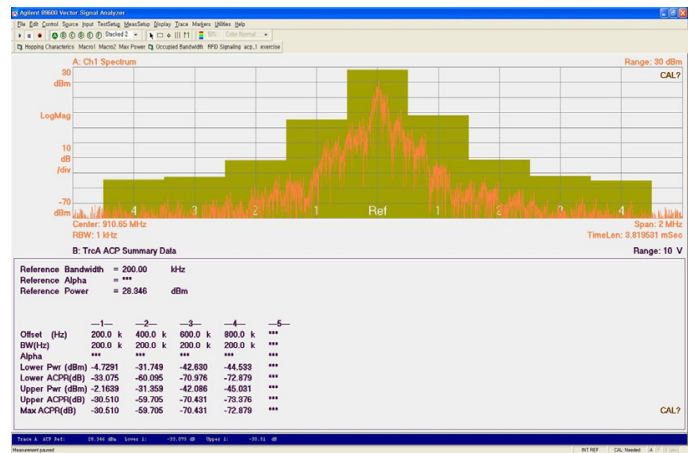

[그림 10] 스팩트럼 마스크 측정 결과

[표 3] 스팩트럼 마스크 측정 결과

\begin{tabular}{|c|c|c|}
\hline 항목 & 규격 사양 & 측정결과 \\
\hline Reference Frequency & $200 \mathrm{~K}$ & $200 \mathrm{~K}$ \\
\hline fc-200k power & $-20 \mathrm{dBch}$ & $-30 \mathrm{~dB}$ \\
\hline fc-400k power & $-50 \mathrm{dBch}$ & $-59 \mathrm{~dB}$ \\
\hline fc-600k power & $-60 \mathrm{dBch}$ & $-70 \mathrm{~dB}$ \\
\hline fc-2800k power & $-65 \mathrm{dBch}$ & $-72 \mathrm{~dB}$ \\
\hline
\end{tabular}

- 리더 명령 Preamble

리더에서 송신하는 명령 신호의 프리앰블(Preamble) 구조와 데이터의 정확도를 확인 하며, 측정 결과는 아래 와 같다.

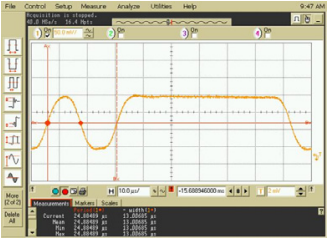

Tari

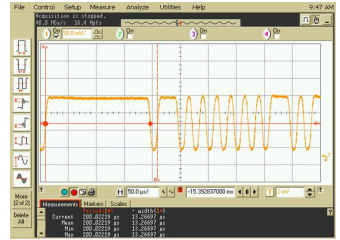

TRcal

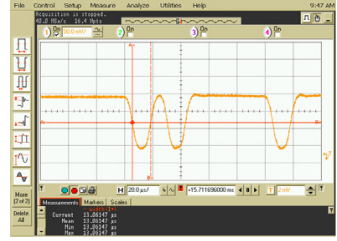

Delimiter
[그림 11] 리더 Preamble 측정 결과

- 리더의 명령 송신타이밍이 국제 표준 규격에 적합하 게 동작 하는 가를 확인한다. T2 Timing 과 $\mathrm{T} 4$ Timing만을 측정.

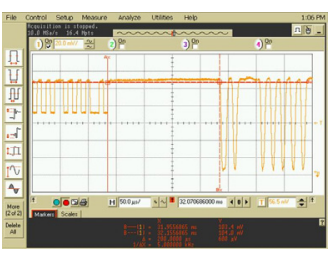

T2 Timing

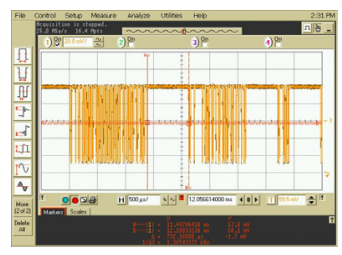

T4 Timing
[그림 12] $\mathrm{T} 2, \mathrm{~T} 4$ 측정 결과

\subsection{2 표준규격 요구 사항 및 측정 결과 비교}

ISO 18000-6 규격[1]에 정의 된 규격 사항과 본 논문 에서 시험한 결과가 국제 표준 규격에 적합한지를 비교 한다.

[표 4] 측정 결과 및 표준 규격 만족항목

\begin{tabular}{|c|c|c|c|}
\hline 항목 & 규젹 요구 사양 & 축정졀과 & 만족여부 \\
\hline Tari & 6.25 us to $25 u \mathrm{~s}$ & $24.8 \mathrm{us}$ & 만죽 \\
\hline ASK modulation Depth & Min $80 \%-90 \%$ & $95.27 \%$ & 만죽 \\
\hline RF: Pulsewidth & $\begin{array}{l}\text { Min: Maxt(0.265 fati, 2us) } \\
\text { Max:0).525Taxi }\end{array}$ & 10. $422 \mathrm{us}$ & 만죽 \\
\hline Rise time & Max 50) us & 4.9058us & 만죽 \\
\hline Fall time & Max 50)uss & 5.1353us & 만죽 \\
\hline T2 time & Min 3 Tari $<12>\operatorname{Max} 20$ Tari & 20) ưs & 만죽 \\
\hline T4 time & $T_{4}>2 R R_{c a l}$ & 732.36 us & 만죽 \\
\hline
\end{tabular}

표 3에서 보여주는 것과 같이 ISO/IEC 18000-6에서 요구 하는 RFID 신호에 관한 사양들을 만족하고 있는 것 을 볼 수 있다. 


\subsection{3 태그 인식 성능 시험}

본 논문에서는 표준 규격에 근거한 태그 인식 성능 시 험을 수행 하지 못했으며 다만 $\mathrm{Lab}$ 환경에서 가까운 거 리에 따른 태그 인식 시험 및 신호 특성만을 시험 하였 다. 국제 표준에 준하는 태그 인식 성능 시험을 하기 위 해서는 전자파차폐실과 같은 전파 간섭이 없어야 하며 각 거리 별, 태그의 방향 등과 같은 조건들을 충족 시켜 주어야만 한다.

태그 인식 성능 시험을 하기 위한 실험 구성은 그림 2 와 같이 제작한 RFID 에뮬레이터, 신호 분석기, 오실로스 코우프, RFID 패치 안테나 그리고 실험 대상 태그로 이 루어져 있다.

태그 인식 시험을 하기 위한 절차는 아래와 같다.

(1) 에뮬레이터를 리더 모델로 동작시켜 표준 규격에서 정의한 명령어를 생성 하여 데이터를 신호 발생기 를 통하여 송출하게 한다.

(2) 대상 Tag에서는 리더의 신호에 따라 응답 신호를 방사한다.

(3) 방사된 신호는 신호 분석기를 통해 수신한다.

(4) 수신한 데이터를 분석 하여 Tag의 UID가 정확 한 지를 판단한다.

위와 같은 방법을 태그의 거리를 이동 시켜 거리에 따 른 인식이 정확한지 여부를 판단한다.

테스트한 결과는 아래와 같다.

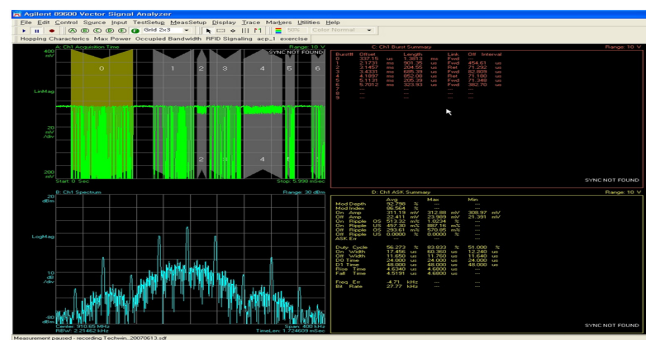

[그림 13] Tag 인식 신호 확인

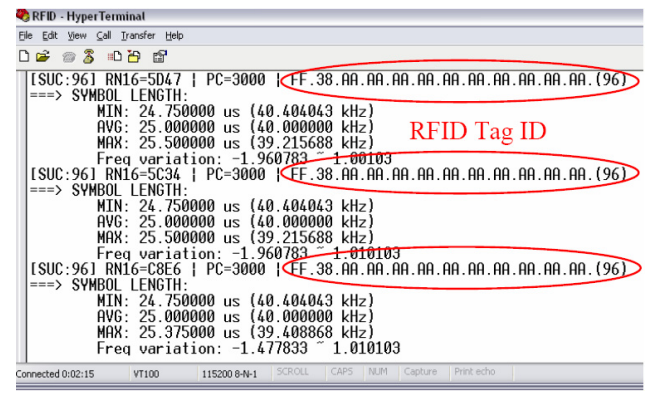

[그림 14] Tag ID 확인
[표 5] 인식거리에 따른 인식 Power

\begin{tabular}{|c|c|}
\hline 인식 거리 & 인식 Power (Mean) \\
\hline \hline $1.96 \mathrm{~m}$ & $29.16 \mathrm{dBm}$ \\
\hline $2.46 \mathrm{~m}$ & $27.2 \mathrm{dBm}$ \\
\hline $3.22 \mathrm{~m}$ & $24.85 \mathrm{~m}$ \\
\hline $3.83 \mathrm{~m}$ & 23.34 \\
\hline $4.34 \mathrm{~m}$ & 22.25 \\
\hline $4.69 \mathrm{~m}$ & 21.57 \\
\hline $5.15 \mathrm{~m}$ & 20.77 \\
\hline 인식 안됨 & 19.54 \\
\hline
\end{tabular}

표 5 에서 보여 지는 것과 같이 인식 Power가 $20 \mathrm{dBm}$ 이하고 떨어지게 되면 Tag 인식이 안 되는 것을 볼 수 있다.

\section{5. 결론}

본 논문에서는 자체 제작한 RFID 에뮬레이터와 신호 발생기, 신호분석기를 연동하여 최근 활발히 개발 중인 ISO 18000-6 Type C의 $860 \mathrm{MHz} 960 \mathrm{MHz}$ RFID 리더 또 는 태그를 측정 할 수 있는 시스템을 개발하였다. 제작한 에뮬레이터는 가상의 리더와 가상의 태그 모델을 이용하 여 베이스밴드 신호를 생성, 분석하는 기능을 구현 하여 실제 리더 또는 태그가 국제표준 규격에 적합한지를 시 험 할 수 있다.

또한 에뮬레이터에서 생성된 데이터를 신호 발생기 및 신호 분석기를 이용하여 가상의 리더 또는 태그로 동작 할 수 있게 하였다. 가상의 태그로 동작 할 경우 대상 리 더에서 전송된 RF 신호를 국제 표준 규격에서 명시한 테 스트 항목을 따라 측정 하여 대상 리더가 국제 표준 규격 을 만족 하는 지를 테스트 할 수 있게 하였다.

에뮬레이터가 가상의 리더로 동작할 경우 국제 표준 규격을 만족하는 리더 명령어를 신호 발생기를 이용하여 송출하면 대상 태그는 그에 따른 응답 신호를 방사한다. 이 신호를 신호 분석기로 수신 하여 RF 특성을 분석 하 고 대상 태그의 UID를 추출하여 정확하게 인식 되었는지 를 테스트 할 수 있다.

향후 과제는 국제표준규격에 정의 되어 있는 요소를 더 반영 하여 보다 완벽한 RFID 에뮬레이터와 국제 표준 규격에서 요구하는 Conformance 테스트 시스템과 소프 트웨어 개발이 필요하며, 국제 표준 규격에서 요구 하는 테스트 환경을 구현하는 것이 필요하다. 


\section{참고문헌}

[1] ISO/IEC "ISO/IEC 18000-6 Parameters for air interface communications at $860 \mathrm{MHz}$ to $960 \mathrm{MHz} "$

[2] EPCglobal "Radio-Frequency Identity Protocols Class-1 Generation-2 UHF RFID Protocol for

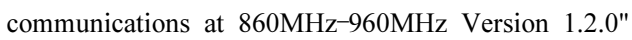

[3] 한국정보통신기술협회 TTAS.KO-06.0132/R1 “모바일 RFID Air Interface RF 표준적합성 시험 규격” 2007년

[4] ISO/IEC "ISO/IEC Radio frequency identification device performance test methods - part3: test methods for tag performance

[5] 표.철.식. 외. 2명., "RFID 시I스템기술”, 한국전자파 학회지 제 5 권제호 2004년

[6] 변 상기 "RFID Tag 기술", 한국전자파학회지, 제5권5 제호 2004년

[7] 박용재외 2명 "RFID/USN 시장 동향 및 서비스 수요 분석” 전자통신동향 분석 제24권 제2호 2009년 4월.

[8] 최 길영 외 4명 "RFID 기술 및 표준화 동향” 전자통 신 동향 분석 제 22권 제3호 2007년 6월

[9] Klaus Finkenzeller "RFID Handbook Second Edition", WILEY, 2004.

\section{김 영 춘(Young-Choon Kim)}

[정회원]

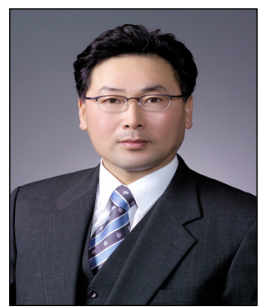

- 1987년 2월 : 대전공업대학교 전 기공학과 (공학사)

- 1989년 8월 : 명지대학교 전기공 학과 (공학석사)

- 1997년 2월 :명지대학교 전기공 학과(공학박사)

- 2006년 3월 현재 : 공주대학 교 기계자동차공학부 교수

<관심분야>

전기자동차전력변환, 전장제어, 하이브리드 자동차

\section{주 해 종(Hae-Jong Joo)}

[정회원]

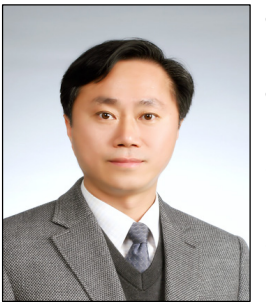

- 2008년 6월 : (美)Cumberland University (교육학박사)

- 2010년 2월 : 명지대학교 컴퓨터 공학과 (공학박사)

- 1997년 3월 2005년 2월 : 대 원대학 멀티미디어과 조교수

- 2010년년 1월 현재 : 동국대 학교 산학협력중심대학 교수

<관심분야>

데이터엔지니어링, IT융합기술, 유비쿼터스비즈니스

\section{최 혜 길(Hae-Gill Choi)}

[정회원]

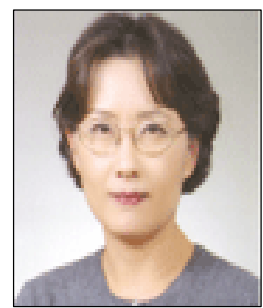

- 1980년 2월 : 연세대학교 생화학 과 (이학사)

- 1986년 5월 : Northern Illinois Univ.(USA) (MS)

- 1999년 2월 : 충남대학교 컴퓨터 과학과 (이학박사)

- 2002년 3월 현재 : 경희사이 버대학교 정보통신학과 교수

<관심분야>

멀티미디어DB, 소프트웨어공학, e-learning 표준화

\section{조 문 택(Moong-Taek Cho)}

[정회원]

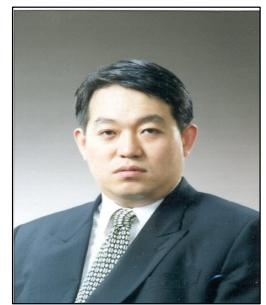

- 1988년 2월 : 명지대학교 전기공 학과 (공학사)

- 1990년 2월 : 명지대학교 전기공 학과 (공학석사)

- 1999년 2월 :명지대학교 전기공 학과(공학박사)

- 2006년 3월 현재 : 대원대학 전기전자계열 부교수

<관심분야>

신재생에너지, 시뮬레이션 